\title{
ALFONSO DE CASTRO, INTER THEOLOGOS IURICONSULTISSIMUS: DE JUSTA HAERETICORUM PUNITIONE, LIBRI TRES. UNA INTRODUCCIÓN *
}

\section{ALFONSO DE CASTRO, INTER THEOLOGOS IURICONSULTISSIMUS: DE JUSTA HAERETICORUM PUNITIONE, LIBRI TRES. AN INTRODUCTION}

\author{
MANUEL LÁZARO PULIDO \\ UNED \\ Universidad Bernardo O’Higgins, Chile
}

\section{RESUMEN}

El presente artículo intenta mostrar la labor de la reflexión jurídica del teólogo en el siglo XVI a partir de Alfonso de Castro del siglo XVI y de su obra De iusta heretecorum punitione. Pensada en tiempo de la Reforma luterana para luchar contra la herejía, teniendo un carácter teórico, no se trata de una obra estrictamente académica. Su fin es la justificación teórica de la lucha jurídica contra el luteranismo, su fin es pues práctico. El estudio presenta al autor en un momento de reforma, su papel de teólogo y jurista, para presentar brevemente la obra en cuestión.

Palabras clave: Alfonso de Castro, teología jurídica, luteranismo, herejía, derecho.

\footnotetext{
* Estudio parte de la investigación doctoral (cap. II) en el programa en Derecho y Ciencias Sociales (Línea05-PD105 - Los principios generales del derecho: fundamentación iusfilosófica, génesis, evolución histórica y concreción jurisprudencial nacional y europea) de la UNED.
} 


\section{ABSTRACT}

This article tries to show the work of the theologian's juridical reflection in the 16th century on the basis of Alfonso de Castro in the 16th century and his work De iusta heretecorum punitione. Thought at the time of the Lutheran Reformation to fight against heresy, having a theoretical character, it is not a strictly academic work. Its aim is the theoretical justification of the juridical struggle against Lutheranism, its aim is therefore practical. The study presents the author in a moment of reform, his role as a theologian and jurist, to briefly present the work in question.

Keywords: Alfonso de Castro, legal theology, Lutheranism, heresy, law.

\section{INTRODUCCIÓN}

Alfonso de Castro nació en Zamora en 1495 y murió en $1558^{1}$. Fue franciscano observante, profesando en Salamanca. Inició su formación en el Estudio General salmantino del Convento de San Francisco y pronto fue, becado por la provincia de Santiago, al Colegio de San Pedro y San Pablo, cursando en la recién erigida Universidad Complutense, en Alcalá, contaba con 16 años.

Una vez regresado a Salamanca y completado sus estudios inicia su labor docente en Teología en el convento de San Francisco ${ }^{2}$, que era el más importante de la provincia franciscana de Santiago ${ }^{3}$. Se trataba de un Estudio General de toda la Orden y, a su vez, un colegio universitario incorporado, manteniendo relaciones con la Universidad del Tormes. Su labor docente fue frecuentemente interrumpida debido a sus compromisos como consejero real e imperial entre los que se incluía su labor predicativa. Así, a partir de 1533 se traslada a los Países Bajos como orador al pedido de los mercaderes españoles, 1lamado a predicar la causa católica ante el peligro que se cernía con la rápida extensión del luteranismo. Pero es a partir de 1545, cuando Alfonso de Castro pasa a ser un

1 Un itinerario clásico de la obra y vida del teólogo zamorano está expuesto de forma suficiente en estudios ya clásicos. No tiene sentido repetirlo tal cual, siguiendo ese formato de exposición, toda vez que los que nos interesa en este capítulo es marcar el carácter humanista y la personalidad multifacética de su figura en aras a enmarcar nuestro abordaje sobre las fuentes indirectas de su pensamiento jurídico. Para su vida y obra remitimos a: Amado González, "Vida y Bibliografía de Fray Alfonso de Castro", Liceo Franciscano 12 (1958): 1-106.

2 Manuel R. Pazos, Los estudios en la provincia franciscana de Santiago (Tratado histórico) (Madrid: Escuelas profesionales Sagrado Corazón de Jesús, 1967), 129-143.

3 Desde que sus inicios, el convento impartió estudios de teología, circunstancia que se extendió hasta 1835. No fue el único caso en la Provincia de Santiago, los conventos de Santiago, Oviedo y León también corrían la misma suerte. Cf. Pazos, Los estudios en la provincia franciscana..., 47-57. 
teólogo al servicio de los intereses de los monarcas. Alfonso de Castro se muestra como ejemplo de la actitud y del modo de proceder frente a las acusaciones de Lutero (1483-1546), no solo por la fuerza dogmática de la controversia, sino por el desarrollo de los estudios de la Sagrada Escritura y moral ${ }^{4}$.

Su itinerario bibliográfico viene definido por tres grandes obras: Adversus omnes haereses libri XIV (1534), De justa haereticorum punitione, libri tres (1547) y De potestate legis poenalis, libri duo (1550). Estas obras reflejan, su itinerario vital e intelectual, en la utilización de una metodología que difiere un tanto de los tratados universitarios de la época, que ya, en sí, representaban una renovación del método teológico.

La personalidad vital e intelectual de Alfonso de Castro viene definida por su carácter multifacético que responde a las circunstancias a las que se enfrenta un franciscano teólogo de su época y que viene marcado por el espíritu de reforma presente en el salto a la Modernidad. Reforma que como teólogo viene de la mano del método teológico, como franciscano del propio espíritu reformista de las órdenes religiosas y como católico del reto -concomitante a lo anteriorde la Reforma protestante.

Una de las señas de identidad que suceden en la época de Alfonso de Castro es el asentado prestigio del teólogo. Este pasará a ser un referente dentro de la Iglesia. Sus opiniones, en cuanto que muestran la referencia última de sentido de la cultura de su tiempo, tendrán un profundo eco en el poder político. Se trata de un prestigio que ya se inicia durante el siglo $\mathrm{XV}$, con el ejercicio efectivo de las Facultades de Teología de la mano del problema conciliarista, y que se ve aumentado y proyectado en el siglo $\mathrm{XVI}^{5}$. Una muestra de ello es el aumento significativo de las facultades teológicas. En el siglo XVI, ante los nuevos retos presentes -especialmente el descubrimiento de América-, desde la renovación teológica que va de la mano del nuevo humanismo -significativamente el hecho de una mirada integral al hombre como lugar de manifestación de Dios- y reforzado por las implicaciones sociopolíticas y eclesiales de la Reforma, el teólogo valora todos los aspectos de la vida humana en relación con la imagen de Dios en lo humano y en lo soteriológico. Los teólogos adquieren un prestigio de gran magnitud: Francisco de Vitoria, Domingo de Soto (1494-1560), Melchor Cano (1509-1560), Alfonso de Castro, Bartolomé de Las Casas (c. 1484-1565) ... son personajes que compiten con los grandes políticos -Carlos V (1500-

4 Miguel Anxo Pena, La Escuela de Salamanca. De la Monarquía hispánica al Orbe católico, (Madrid: BAC, 2009), 8.

5 Melquiades Andrés, "La Teología en el siglo XVI (1470-1580)", en Historia de la Teología Española. I. Desde sus orígenes hasta finales del siglo XVI, dir. por Melquiades Andrés (Madrid: Fundación Universitaria Española, 1983), .595-596. 
1558) o Felipe II (1527-1598)- y literatos como Cervantes (1547-1616) o Luís de Camões (1524-1580).

Este prestigio viene de la mano de la perfección del método teológico, que durante tiempo había sido dominado por un verbosismo que terminaba por ser inútil y autorreferente ante la apertura que el mundo estaba experimentando. La nueva forma de hacer teológica viene de la mano de la adopción del humanismo aplicado al método expositivo (junto a la disputatio se tendrá en cuenta la oratio), de la hermenéutica y la exégesis bíblica (el trabajo de las biblias romanceadas), así como de la apertura a los diferentes caminos de interpretación de la teología sistemática, lo que se conoce como las "tres vías, que supone la adopción de una mentalidad capaz de aunar reforma y tradición a partir de una importante Facultad de Artes ${ }^{6}$. Luis Miguel Gutiérrez Torrecilla señala que la introducción de este método teológico (el de las tres vías) supuso "un revulsivo para revitalizar un estudio que ya en aquella época tendía a ser repetitivo y escasamente creativo"7. Esta adopción pasa a la universidad del siglo XVI, pero tiene como lugar pionero el trabajo de los profesores complutenses, quienes debían saber comentar y escribir los tratados filosóficos y teológicos "según las tres vías". Esto supuso un enorme enriquecimiento doctrinal, una seguridad teológica y un enorme pluralismo.

Hablar de la reforma y de la Orden de Hermanos Menores es casi un eufemismo. La Orden franciscana tuvo desde el principio un carácter de interpretación del espíritu que animaba al Fundador. La fuerza del espíritu franciscano lleva a la Institución a no relajarse, pues el Evangelio no permite dormir y exige estar siembre en vela. Esta exigencia interna de seguimiento a Jesús pobre y crucificado mantuvo la tensión entre intuición e institución ${ }^{8}$. Así, en el siglo XV, en el seno de la Orden franciscana se viven experiencias reformadoras, eremitorios y oratorios donde vivir la "vuelta a la integridad de la Observancia regular y de la vida espontánea" . Siendo paradigmática la forma franciscana del eremitismo, la verdad es que lo que hacen los franciscanos de la época es adoptar como estrategia de vuelta a la vida de la intuición franciscana una forma ya presente en su tiempo. Así, a la intrínseca orientación reformista franciscana, entendida como una continua vuelta a los principios de la regla, se le sumó un

6 Juan Urriza, La preclara Facultad de Arte y Filosofia de la Universidad de Alcalá 1509-1621 (Madrid: CSIC, 1941).

7 Luis Miguel Gutiérrez. "Aproximación a la historia de la Universidad de Alcalá (siglos XVIXIX)”. Indagación. Revista de historia y arte 0 (1994): 26.

8 Théophile Desbonnets, De l'intuition à l'institution. Les franciscains (Paris: Éditions Franciscaines, 1992).

9 José García, "Conventualismo y Observancia", en Historia de la Iglesia en España. III/1. La Iglesia en la España de los siglos XVy XVI, ed. por Ricardo García-Villoslada (Madrid: BAC, 1980), 237. 
momento histórico con ansias de reforma. Entre los religiosos de la época, el concepto de reforma tiene como referencia la vuelta a los orígenes de las diferentes religiones desde el fundamento de la vuelta al espíritu evangélico.

El movimiento reformista expresa una salida, una respuesta, a un momento de cierta decadencia en el seno de la Iglesia a inicios del siglo XV. Síntomas de este decaimiento eclesial es la bajada del tono teológico y religioso, que se refleja en las heridas abiertas marcadas por el problema cismático y que se expresan en la contestación a la autoridad sacramental de los Lolardos en Inglaterra ${ }^{10}$ o los Husitas en Bohemia ${ }^{11}$ o de, en la corrupción disciplinar en las órdenes monásticas y mendicantes y la degradación de la institución papal a la que le sigue, en consonancia, tanto la cuestión "conciliarista" 12 , como la crisis moral que acompaña a los Papas renacentistas de la segunda mitad del siglo XV incapaces de asumir las reformas necesarias en la Iglesia.

Ante este relajamiento, la Reina Isabel y el cardenal franciscano Cisneros reaccionarán. La reforma religiosa es el primer puntal para poder desarrollar una reforma más amplia y con una proyección católica (universal) de carácter misionero, entiéndase en un proyecto de cristianización como proyecto cultural y global y, por lo tanto, social y político ${ }^{13}$.

Pero este relajamiento, rodeado de un contexto filosófico y teológico determinado dará lugar a la Reforma protestante. La Reforma protestante no supone solo una interpretación religiosa con efectos eclesiológicos e institucionales, sino que, en este momento de la historia, donde la teología juega un papel, como hemos señalado, de orientación cultural, social y política, implica un reto civilizacional, justo en el momento en el que se está constituyendo un Nuevo Mundo. El catolicismo se entiende de forma evangélica, pero como horizonte referencial del tiempo nuevo.

El catolicismo es una nota o característica de la Iglesia que supone la universalidad de la fe cristiana y del mensaje evangélico. Esta universalidad se puede entender de forma exclusiva o inclusiva. De forma exclusiva, supone que la catolicidad es un signo de una iglesia frente a otras formas de cristianismo

10 Gordon Leff, Heresy in the Later Middle Ages, vol. 2. (Manchester: Manchester University Press, 1967), 494-573.

11 Ver la clásica obra: Paul De Vooght, L'hérésie de Jean Huss (Louvain: Publications Universitaires de Louvain, 1960).

12 Un análisis histórico-teológico, con tendencia a la simpatía por las tesis conciliaristas en Giuseppe Alberigo, Chiesa conciliare: Identità e significato del conciliarismo (Brescia: Paideia Ed. Istituto per le Scienze Religiose, 1981).

13 José García y Segundo L. Pérez, "La reforma religiosa durante la gobernación del Cardenal Cisneros (1516-1518): hacia la consolidación de un largo proceso", Annuarium Sancti Iacobi 1 (2012): 49. 
que se constituyen desde la desviación, es decir, la herejía. Así, si el siglo XV supone la división en el seno del papado y la diferencia con la Iglesia ortodoxa. En el siglo XVI el catolicismo es lo que se diferencia de la «herejía» del protestantismo. Entendido así, solo existe catolicismo haciendo converger las desviaciones hacia la doctrina de la Iglesia católica. Surge el proyecto del Orbe católico (el nuevo Imperio para el nuevo tiempo). De forma inclusiva, el catolicismo supone la oportunidad de construir un nuevo mundo como tiempo del Espíritu, un nuevo proyecto apocalíptico que implica la purificación espiritual de toda la humanidad: un hombre nuevo, una nueva Iglesia, un nuevo cielo y una nueva tierra, un nuevo tiempo. El problema estriba en que en un espacio dividido resulta difícil su realización. A finales del siglo XV e inicios del siglo XVI aparece el nuevo espacio, la nueva tierra, y los franciscanos serán protagonistas de esta acción, especialmente, en el Nuevo Mundo, que se va a convertir en un lugar privilegiado donde poder probar nuevos proyectos sean filosóficos, científicos, políticos y religiosos. Pero también ante el Mundo Nuevo, a través de su esfuerzo predicador y teológico. Efectivamente, la predicación mendicante atendió, con frecuencia, a la pacificación, la reconciliación y la conversión, primordialmente en las urbes. Tenemos ejemplos ad intra, como el caso, en 1484, de los frailes franciscanos de San Francisco de Jerez que consiguen frenar las tensiones ocasionadas entre los propios hermanos, los dominicos y los mercedarios $^{14}$; y ad extra con la constante llamada a los franciscanos a predicar frente al problema de los herejes. Por otra parte, es habitual también que "el predicador mendicante sea a la vez vocero y emisario pontificio para las grandes causas de la Cristiandad" 15 . En este oficio destaca la labor de Alfonso de Castro, al que se le sumó su oficio de teólogo-jurista, que pondrá racionalidad jurídica a la predicación contra la herejía, convencido de que siendo la predicación la labor pedagógica fundamental para evitar la herejía, es la orientación jurídica la que debe actuar cuando lo primero no ha sido eficaz. Esta orientación jurídica evitará, por su parte, cualquier arbitrariedad y nominalismo jurídico-teológico.

\section{INTER THEOLOGOS IURICONSULTISSIMUS ${ }^{16}$}

Melquiades Andrés, hablando de Francisco de Victoria, señalaba que al maestro dominico se le conocía más como jurista que como teólogo, y de hecho

14 José García, Los Franciscanos en España. Historia de un Itinerario Religioso (Santiago de Compostela: El Eco Franciscano, 2006), 75.

15 García, Los Franciscano en España...,76.

16 Cf. Manuel Lázaro, "Posiciones antropológico-jurídicas en el Tratado La fuerza de la ley penal de Alfonso de Castro", en Razón práctica y derecho. Cuestiones filosófico-jurídicas en el Siglo de Oro español, ed. por Juan Cruz (Pamplona: Eunsa, 2011),138-143. 
había más estudios sobre él desde la perspectiva jurídica que teológica ${ }^{17}$. Esto es extensible a Alfonso de Castro de quien podemos decir que de los estudios que tenemos de él, es la faceta jurídica la que se ha cuidado de una forma especial, pero como Vitoria y los teólogos de su generación, ellos no dejan de ejercer su función intelectual por la que son reclamados en tanto que teólogos. Y como teólogos iluminan la última referencia de la lectura del derecho en la que se forman los juristas de la época y que al Derecho consuetudinario -Derecho positivo-y el antiguo Derecho nacional (en la Península ibérica tendrá gran peso el código alfonsí), es decir, el Derecho propio, se le suma el Derecho técnico, la intercesión entre el Derecho romano -especialmente a partir del siglo XI-, el Derecho canónico - que, a la vez, había recepcionado parte del Derecho romano ${ }^{18}$-, forjando, así, una racionalidad normativa que afectará a las diferentes ramas del derecho e instituciones jurídicas y políticas ${ }^{19}$. Así, pues, el Derecho español nacerá del utrumque ius, de la lectura conjunta, a partir del Derecho técnico -Derecho romano y Derecho canónico-, de modo que el Derecho civil no podrá olvidar este tronco común. Este fenómeno conocido como "recepción romano canónica" 20 , tiene lugar en la Baja Edad Media, es decir, en el momento en el que el Derecho canónico se consagra como ciencia. El tiempo de Alfonso de Castro es el momento previo a la consagración del Corpus iuris canonici, promulgado por Gregorio XIII, en 1582, y, por extensión, de la transformación nominativa del Corpus iuris Justiniano, en Corpus iuris civilis: "en la Edad Moderna, precisamente, ese Derecho nacional está lleno de elementos romano-canónicos, de tal manera que, en el último tercio del siglo XVI, se dará una fuerte tensión, cuyo resultado se plasmará en los Códigos civiles, que contendrán básicas fundamentaciones romano-canónicas" ${ }^{21}$. Acaso, la forma de enfrentar este fondo común, esta recepción romano-canónica presente en el fondo jurídico común europeo, será una de las fronteras existentes entre la reflexión penal de Alfonso de Castro y el tono crítico de Beccaria en De los delitos y las penas ${ }^{22}$.

17 Melquiades Andrés, La teología española en el siglo XVI, Vol. 2 (Madrid: BAC, 1977), 360. Del mismo modo se expresaban Ricardo García-Villoslada, "Fray Francisco de Vitoria, reformador de los métodos de la teología católica", en Fray Francisco de Vitoria, fundador del derecho internacional moderno (Madrid: Cultura Hispánica, 1946), 65-66 y Juan Belda, La Escuela de Salamanca y la renovación de la teología en el siglo XVI (Madrid: BAC, 2000), 317.

18 José Miguel Viejo, "La recepción del derecho romano en el derecho canónico", Ius ecclesiae 14 (2002): 375-414.

19 Gabriel Le Bras, "La formation du droit romano-canonique", en Actes du congrès de droit canonique, Cinquantenaire de la Faculté de droit canonique de l'Institut catholique de Paris (1947), dir. por Pierrre Andrieu-Guitrancourt (Paris: Letouzey et Ané, 1950), 335-338.

20 Cf. John Henry Merryman y Rogelio Pérez-Perdomo, La tradición jurídica romano-canónica, $3^{\mathrm{a}}$ ed. (México: Fondo de cultura Económica, 2014).

21 Jaime Pérez-Llantada, "Derecho civil (ius civile)", en Diccionario de Derecho canónico, dir. por Carlos Corral, $2^{\mathrm{a}}$ ed. (Madrid: Tecnos, 2000), 222.

22 Manuel Santaella, Montesquieu. El legislador y el arte de legislar (Madrid: UPCO, 1995), 36. 
En España, el sistema procesal penal en los tribunales y juzgados mantenían la recepción romano-canónica, esta, junto a la doctrina comentada, se constituían en el criterio hermenéutico.

Como señala Rouco Varela, de la mano del Derecho canónico y del Derecho romano, ambos entretejidos, a nivel teórico-jurídico y vital-personal, se encarna la "figura del jurista medieval, muchas veces laico, del Doctor iuris utriusque", erigido sobre el mismo trasfondo histórico y filosófico, y que en se verá más claro en las tensiones políticas entre imperio y papado del siglo XIV ${ }^{23}$. No es de extrañar, pues, que los teólogos de la época pongan en evidencia con sus reflexiones la penetración teológica que existe entre la ley y la teología. Como hemos señalado, entre el hombre, imagen de Dios, y la comunidad eclesial y social en la que vive. Esta última no es ajena al desarrollo salvífico del hombre. Así, pues, no es de extrañar que el derecho se vea afectado por la influencia de la reflexión teológica y religiosa judeocristianas o específicamente bíblicas, surgiendo así la función del teólogo-jurista.

\section{EL TEÓLOGO-JURISTA}

Alfonso de Castro era doctor y profesor en el Real Convento de San Francisco, es fácil de imaginar que pasara también por las mismas aulas de la Universidad, aunque el hecho de pertenecer a un Colegio agregado a la universidad le hacía partícipe de la estructura universitaria y, por lo tanto, de un magisterio universitario. Alfonso de Castro no es, ni se considera, un jurista, sino un teólogo que opera su razonamiento teológico en aras a la fundamentación de la práctica jurídica, por lo tanto, un teólogo que se interesa por los temas jurídicos, como era el caso de Francisco de Vitoria, Domingo de Soto, Mancio de Corpus Christi (c.1500-1576), Bartolomé de Medina (1497-1585), fray Luis de León (1527-1581), Domingo Báñez (1528- 1604), Pedro de Aragón (c. 1546-1592), Pedro de Ledesma (1544-1616), Matías de Paz (c. 1470-1519), Juan Gallo (1520-1578), Juan de la Peña (1513-1565), Juan de Guevara (1518-1600) y otros $^{24}$. Alfonso de Castro es con frecuencia objetivo de diálogo sobre la definición y naturaleza de la Ley y del Derecho con sus coetáneos como Soto o Fernando Vázquez de Menchaca (1512-1569).

Esta circunstancia no disminuye su capacidad de razonamiento jurídico. Alfonso de Castro, no siendo un jurista en sentido estricto, sin embargo, será

23 Antonio María Rouco, Teología y Derecho: escritos sobre aspectos fundamentales de Derecho Canónico y de las relaciones Iglesia-Estado, ed. por Roberto Serres (Madrid: Cristiandad, 2003), 85-86.

24 Salustiano de Dios, "Corrientes jurisprudenciales siglos XVI-XVII", en Historia de la Universidad de Salamanca: Saberes y confluencias, 3/1..., 110. 
reconocido en la historia por su reflexión jurídica. Es un teólogo en la época, como hemos visto al inicio de este capítulo, en el que la teología es la ciencia que vertebra el pensamiento, toda vez, que ella suma la pluralidad de fuentes, en un razonamiento lógico, dentro de una cosmovisión vertebrada sobre Dios, el hombre y el mundo, desde la visión sobrenatural a la mirada natural (en ello espacial y temporal): Dios, uno y trino, Primer Principio y Creador; el hombre, ser creado personal e imagen; el mundo creado como natura y como naturaleza - distinción alfonsí que señala la naturaleza física (las cosas en relación) y la naturaleza jurídica (la esencia del sujeto jurídico de las personas en la sociedad de los seres humanos que viven en la comunidad política y de los hombres creados a imagen de Dios que constituyen la comunidad eclesial) en su devenir y en su historia ${ }^{25}$.

La faceta jurídica de Alfonso de Castro se entiende dentro de la dinámica canonista de la Universidad de Salamanca, que conoce un crecimiento exponencial ya en el siglo XV. Antonio García señalaba al respecto como "en el siglo $\mathrm{XV}$ florece toda una pléyade de canonistas con una producción literaria digna de ser conocida. Sus escritos - continúa diciendo-, inéditos en su mayoría, yacen sepultados en sus bibliotecas y archivos, esperando que la atención de los estudiosos recaiga sobre ellos. La aureola de fama de que gozan nuestros grandes maestros de los siglos XVI-XVII pudo contribuir a proyectar un cierto olvido sobre sus inmediatos predecesores" 26 .

Sin duda alguna, una mirada a la bibliografía sobre el teólogo franciscano muestra que una gran parte de los estudios sobre él pivotan en torno a esta faceta y a su obra señera: el De potestate legis poenalis. Sin duda, mucho ha influido en la figura de Alfonso de Castro y la importancia de su contribución a la ciencia del derecho, el estudio de Marcelino Rodríguez Molinero, Origen español de la ciencia del derecho penal. Alfonso de Castro y su sistema de derecho penal. ${ }^{27}$

La importancia de la reflexión jurídica ha sido reconocida en vida y recordada siempre, incluso más allá de nuestras fronteras ${ }^{28}$. Su contemporáneo Juan

25 Manuel Lázaro, "La naturaleza de la natura: un apunte sobre mística y ciencia en el franciscanismo medieval de la Península Ibérica", Scientia et fides 6/2 (2018): 129-146.

26 Antonio García, "Juristas salmantinos, siglos XIV-XV: manuscritos e impresos", en Historia de la Universidad de Salamanca, Vol. 3/1, ed. por Luis E. Rodríguez-San Pedro y Juan Luis Polo (Salamanca: Publicaciones universidad de Salamanca, 2006), 121.

${ }^{27}$ Marcelino Rodríguez, Origen español de la ciencia del derecho penal. Alfonso de Castro y su sistema de derecho penal (Madrid: Ed. Cisneros, 1959), esto obra conoce una nueva edición revisada en Marcelino Rodríguez, Alfonso de Castro y su doctrina penal. El origen de la ciencia del derecho penal (Pamplona: Eunsa, 2013).

28 Es sugerente ver una bibliografía reciente en Alemania donde podemos destacar los siguientes trabajos: Harald Maihold, "Systematiker der Häresien - Erinnerung an Alphonso de Castro (1492-1558)", 
Gallo se refería a él, en los siguientes términos: "inter theologos iuriconsultissimus, inter iures peritos, in sacris litteris eruditissimus". Esta caracterización pone en evidencia su faceta especulativa teológico-jurídica, su pericia jurídicopráctica, y su erudición teológico-práctica, interrelacionada.

Si bien su figura no he recibido posteriomente, el reconocimiento que merece, en parte por todo el bagaje ideológico de la historiografía derivada de la modernidad, esto no significa que haya sido totalmente olvidado. Algunos especialistas en el ámbito del derecho y, entre ellos, los que han investigado la historia de la ciencia jurídica del derecho penal lo han tenido, al menos, presente. El historiador de la filosofía Eloy Bullón escribía, el primer año del siglo pasado, un libro consagrado a analizar las aportaciones del fraile zamorano al derecho penal, donde reivindicaba la originalidad de su estudio frente a la atribución que hasta entonces se hacía a Cesare Beccaria ${ }^{29}$, y allí señalaba su gran maestría: “es tanto más de extrañar cuanto es más grande la figura del egregio sabio español no sólo por su vasto saber teológico, sino principalmente por los profundos escritos con que ilustró las cuestiones jurídicas" 30 . Por su parte, el catedrático de Derecho Penal, Juan del Rosal afirmaba, en el prólogo a la selección de obras que realizó sobre Alfonso de Castro, la primacía de su figura en el pensamiento clásico $^{31}$. Y si bien no se ha discutido la eminencia teológica y jurídica de Alfonso de Castro, sí es cierto que se ha objetado su excelencia como penalista, anotando en ella una cierta mitificación que ha sobredimensionado su trascendencia a juicio de algunos. Ya Juan de Rosal de forma ponderada expone que para entender bien los presupuestos del pensamiento de Alfonso de Castro es necesario tener en cuenta que "no es un penalista, en el sentido con que hoy se emplea el vocablo... antes que nada es un teólogo, de probada profundidad y

\footnotetext{
Zeitschrift der Savigny-Stiftung für Rechtsgeschichte, Kanonistische Abteilung 118 (2001): 523-530; Daniela. Müller, "Ketzerei und Ketzerbestrafung im Werk des Alfonso de Castro", en Die Ordnung der Praxis. Neue Studien zur Spanischen Spät-scholastik, ed. por Frank Grunert y Kurt Seelmann (Tübingen: Max Niemeyer Verlag, 2001), 333-348.

29 Ver el análisis comparativo del final del libro Eloy Bullón, Alfonso de Castro, fundador del Derecho Penal (Madrid: Imp. Hijos de M. G. Hernández, 1900). Afirmación que es reiterada posteriormente por Jerónimo Montes, Precursores de la Ciencia Penal en España y las causas y remedios del delito (Madrid: Lib. General V. Suárez, 1911) o en Quintiliano Saldaña, reiterando la falsa atribución del origen de la ciencia penal a Italia y que manifiesta en el prólogo de la obra Jaime Maseveu, Contribución al estudio de la Escuela penal española (Madrid: Gráfica Ambos Mundos, 1922), donde afirma: "No se adelantó Italia a otros países en su literatura penal ni en el estudio de los puntos singulares de esta ciencia como la abolición del tormento. Antes lo habian hecho Luis Vives..." (XV).

30 Bullón, Alfonso de Castro..., 8

31 Alfonso de Castro, Antología, selección y prólogo de Juan del Rosal (Madrid: Ediciones Fe, 1942), 7.
} 
genuinamente español, con la cargazón histórico-política de aquel tiempo" ${ }^{\text {"2 }}$. En este sentido, podemos señalar las críticas a la profundidad de la mirada de Castro vertidas por A. Mostaza ${ }^{33}$ y las de F Tomás y Valiente ${ }^{34}$, siempre desde los presupuestos, ya caducos en lo conceptual y presentes en lo ideológico, de las ponderaciones injustas del adamismo cultural.

La divergencia en la valoración de la figura del franciscano zamorano, sin embargo, pone en evidencia la riqueza de matices de su pensamiento. La afirmación de Francisco Tomás y Valiente donde señala que el fraile franciscano debe ser estudiado más como filósofo que como jurista ${ }^{35}$, a nosotros no nos disgusta, ni, creemos, minusvalora su figura en la conceptualización filosófica (teológica) de Alfonso de Castro como figura digna de estudio, en tanto que conceptualizador del derecho penal y como pionero en la reflexión filosófica sobre la ley penal. Más bien, nos complace, pues confirma -o al menos no la deja como descabellada- la intuición que tenemos a priori de que la formación escolástica-teológica de Alfonso de Castro no podía caer en el olvido y que dejaba traslucir un gran acervo filosófico y teológico que merita empezar a ser desbrozado.

Los estudios, pues, sobre la filosofía de la obra de Alfonso de Castro, no son novedosas, ni mucho menos. Hemos visto que su obra ha sido señalada por varios autores de finales del siglo XIX y de principios y mediados del $\mathrm{XX}^{36}$. Sin embargo, no está de más acentuar su vinculación con las posiciones antropológico-jurídicas, y cómo estas responden a cuestiones sistemáticas y prácticas. Subyace en toda consideración teológico-jurídica una concepción filosófica del hombre que sustenta derechos y obligaciones, un sujeto jurídico que tiene un armazón real más allá del mero concepto técnico. Más aún cuando se trata de un probado teólogo.

Alfonso de Castro, a lo largo de su vida, tuvo que hacer frente a no pocos problemas filosóficos que tenían que ver tanto con el trasfondo conceptual y

32 Juan del Rosal, "Prefacio", en Alphonsus a Castro, De potestate legis poenalis, Vol. 1. II [ed. facsímil Ed. Príncipe, Salamanca, Andreas de Portonariis, 1550] (Madrid: Analecta Editorial, 1961), XIII. En esta obra usaremos esta traducción cuando sea posible.

33 Antonio Mostaza, "La ley puramente penal en Suárez y en los principales merepenalistas", Boletín de la Universidad de Santiago de Compostela (1950): 189-241.

34 Francisco Tomás y Valiente, El Derecho penal de la Monarquía absoluta (siglos XVI-XVII-XVIII) (Madrid: Tecnos, 1969), 90-92.

35 Tomás y Valiente, El Derecho penal..., 90-92.

36 Constante Amor y Neveiro, Examen crítico de las nuevas escuelas de derecho Penal (Madrid: Imprenta del Asilo de huérfanos del Sagrado Corazón de Jesús, 1899) 18; Domingo Savall, "Fr. Alfonso de Castro (1495-1558). La orientación voluntarista de su derecho penal", Revista de Archivo Ibero-Americano 38 (1935): 250; Wernz Vidal, Jus Canonicum. VII: lus poenale ecclesiasticum (Romae: Apud Aedes Universitatis Gregorianae, 1937), 23. 
metafísico que afectaba a la teología a través del nominalismo, como con la correcta interpretación de la antropología que sustentaba el humanismo renacentista de la época. Revelando un espíritu realmente humanista, aunque católico, y manifiestamente integrador, no descuida la lectura de los nuevos autores. Erasmo está entre sus lecturas, pero no se trata de una lectura acrítica, ni mucho menos. Una persona cultivada debe examinar las nuevas doctrinas, por lo tanto, se debe aconsejar a los lectores, tanto el cuidado de la nueva literatura, como el hecho de no descuidar el conocimiento y el acercamiento lector de alguna de estas nuevas obras. Alfonso de Castro recomienda esto siempre que se tenga una sólida formación filosófica y humanística, es decir, un conocimiento de los clásicos. Él mismo invitaba la lectura de los grandes filósofos griegos Platón y Aristóteles, así como la de la obra de Cicerón en literatura latina o de Plinio el Joven (61-c. 112) como ilustrado historiador ${ }^{37}$. No es de extrañar que las fuentes humanistas y filosóficas se dejen ver en la obra De potestate legis poenale.

Como no puede ser de otra forma $-\mathrm{y}$ esto es algo que a nosotros nos parece de suma importancia-, el espíritu franciscano aflora en el maestro zamorano. Pero no en una dependencia exclusivista. Es decir, no nos referimos tanto a su franciscanismo en cuanto que sirve a una Escuela determinada, llámese ockhamismo o escotismo. No se trata de un autor de escuela, sino de un autor de época. Se trata de un pensador que toma en serio el espíritu de libertad que siempre dominó en la Orden franciscana. Evidentemente, conoce a los grandes maestros de las primeras generaciones de pensadores franciscanos, aquellos que crearon una Escuela que aún sigue aportando grandes intuiciones al pensamiento filosófico-teológico. Por supuesto, entre sus lecturas y estudios están san Buenaventura (1217-1274), Pedro Juan Olivi (1248-1298), Juan Duns Escoto (12661308)) y Guillermo de Ockham (c. 1287-c. 1347), por citar algunos maestros franciscanos significativos de las diversas generaciones tempranas. Pero, insistimos, Alfonso de Castro, y esto es un signo de su profunda inteligencia y de su intenso franciscanismo, ha sabido asimilar el verdadero carácter de la Escuela que llamamos franciscana: la libertad de interpretación de los autores de su tiempo en el contexto vital en el que se desenvuelve cada pensador. Es cierto que la libertad de los primeros maestros era más acentuada que en los tiempos de Alfonso de Castro, una vez que la Orden había creado sus propios planes de estudio y con la presencia de una tradición establecida por grandes figuras y maestros. Pero, a pesar de la coloración, fray Alfonso es un hombre de

37 Alphonsus a Castro, De justa haereticorum punitione, libri tres, lib. 3, cap. 3, en Opera Omnia, vol. II (Madrid: Ex Typpographia Blassi Roman, 1773), 202b B-C. Las obras de Alfonso de Castro las citamos, al no ser que sea por una circunstancia especial, por esta edición, señalando el volumen en el que s e inserta la obra que se cite. 
interpretación positiva de la realidad, en un ámbito filosófico-moral, que tendrá eco en su interpretación del derecho.

El espíritu franciscano se ve, también, reflejado en la presencia del pensamiento agustinista, a pesar del reconocimiento a la figura filosófica de Aristóteles. Presencia que se deja traslucir en la importancia dada a la Sagrada Escritura como criterio fundamental de saber y de guía en las cuestiones filosóficas y teo$\operatorname{lógicas}^{38}$. La constante referencia a la Escritura supone la primacía, que no exclusividad, de la revelación como criterio de demarcación en la determinación de la verdad ante la insuficiencia de la "sola razón". Y en esto han de ser cautos, para fray Alfonso, los teólogos, quienes no pueden entenderse como tales cuando reducen sus argumentaciones fundamentales a la presentación comentada de Aristóteles. Interpretar al gran Filósofo está bien, pero es insuficiente. Efectivamente, ante la exégesis de un texto de la Escritura -concretamente al profeta Nahúm- realizada por algunos teólogos -y que él califica irónicamente de "sutil"- realiza una declaración clara sobre lo que venimos diciendo:

"No puedo menos que admirarme, y hablando más claramente, no puedo menos de lamentarme, al considerar la temeraria audacia de este y de algunos otros, que no se avergüenzan de calificarse teólogos rematados y apenas entienden un lugar oscuro de los sagrados libros. Estos tales creen tener bastante con investigar el criterio de Aristóteles y todos sus esfuerzos los encaminan a que en todas las disputas aparezca una opinión que recuerde la de aquel filósofo. Por esto, siempre que tratan asuntos teológicos no dejan de caer de la boca el nombre de Aristóteles, como si fuera divino"39.

Aquí, Alfonso de Castro muestra otra característica propia de la Escuela franciscana: la libre interpretación y uso de Aristóteles. Salvando las circunstancias temporales, parece que podemos ver una sintonía con los primeros maestros, quienes, como señala el profesor Francisco Martínez Fresneda, tienen en cuenta al gran filósofo griego, "pero con la libertad de modificarlo o adaptarlo a la Escritura ante las interpretaciones no acordes con las verdades tradicionales de fe, de forma que combinan al Estagirita con el pensamiento neoplatónico agustiniano" ${ }^{40}$. De ahí, que resulte totalmente coherente la continuación del

38 Claudio Gancho, "La Biblia en Alfonso de Castro", Salmanticensis, 6 (1958): 323-349.

39 "Non possum certe non admirari vel ut verius dicam, non ingemiscere, considerans istius \& quorumdam aliorum temerariam audaciam, qui se absolutos Theologos reputare non verentur, cum tamen vix locum unum difficilem sacræ scripturæ intelligant. Satis sibi esse putant; si Aristotelis mentem perceperint: \& ad hunc scopum omnes suas disputationes potissimum dirigunt, ut aliquid Aristotelis sententiæ proximum tractent. Et ob hanc causam Aristotelem, tamquam si divinus ille esset, sere semper cum de Theologica differunt, versant in ore". Alphonsus a Castro, De potestate legis poenale, lib. 1, cap. 8, II, 285b C-D (288).

40 Francisco Martínez, "Textos y contextos de la teología franciscana", en Manual de Teología franciscana, ed. por José Antonio Merino y Francisco Martínez, Madrid: B.A.C., 2003), 20. 
texto anterior y las subsiguientes afirmaciones de Alfonso de Castro cuando declara que:

"Yo ciertamente concedo a Aristóteles más valor que a ninguno otro de los escritores desprovistos de la luz del Evangelio; pero no llego al extremo de admitir, que las cuestiones teológicas desconocidas por completo de él hayan de encauzarse dentro de las reglas por aquel expuestas como hasta ahora han hecho algunos teólogos en sus investigaciones. Precisamente por esto -continúa con una exhortación en la que aparece toda su fuerza y sutileza dialéctica, así como la vena retórica del gran predicador que era-, a muchos autores sensatos agradaría que se enseñara una teología más pura y más sincera: que tuviera más de las divinas Escrituras que de doctrina aristotélica"41.

Además de su experiencia en la docencia ejercida durante tantos años en Salamanca, y de su profundo conocimiento de la Sagrada Escritura, atestiguada, como hemos ya señalado, en sus obras, se deja sentir en esta cita, el espíritu franciscano y la inspiración y conocimiento del pensamiento de Escoto. El recurso a la Sagrada Escritura, además, resulta muy revelador, tanto de la época como de la injusticia de no pocas lecturas acusadoras al franciscanismo sobre la influencia en el espíritu protestante. Precisamente el auxilio al conocimiento de la Sagrada Escritura, y el equilibrio entre el pensamiento teológico y el filosófico, así como la libertad frente a la interpretación exagerada de la filosofía aristotélica eran, en verdad, el mejor antídoto contra el luteranismo, pues no hacía sino realizar, en la ortodoxia y en la justa interpretación, una lectura ajustada de las relaciones entre fe y razón y entre las interpretaciones filosóficas, de modo que se alejaran de un reduccionismo al pensamiento de la filosofía natural y la lógica dialéctica retirada de la metafísica.

Tanto en Adversus omnes haereses, como en la literatura homilética, la razón no constituye - en tanto que disputatio- el principio propio de la afirmación de la ortodoxia de las verdades teológicas, recayendo esta en otras cinco armas propiamente teológicas, a saber: la Sagrada Escritura, las definiciones conciliares, el consentimiento universal de la Iglesia, el juicio (sentencia) de la Sede Apostólica, y, por último, el criterio unánime y conforme de los Santos Padres ${ }^{42}$. Pero ello no supone desdén sobre la razón, ni mucho menos, sino la constatación

41 "Ego quidem Aristoteli tantum tribuo, quantum nulli alteri homini fidei lumine destituto; non tamen adeo illum aestimo, ut putem res Theologicas quas ille prorsus ignoravit, per solas illius regulas esse dirigendas, prout multi Theologi de similibus rebus disserentes hanctenus fecerunt. Ob quam causam á multis prudentibus viris desideratur, ut-Theologia purior, \& sincerior traderetur, quæ, plus divinarum scripturarum, quam Aristotelicae doctrinae contineret". Alphonsus a Castro, De potestate legis poenale, lib. 1, cap. 8, II, 285b B-C (en paréntesis la página de la traducción, 288-289).

42 Saturnino Arias, "Herejía y hereje en Alfonso de Castro", Liceo Franciscano 12 (1958): 117-122. 
del nuevo método teológico humanista y en su tiempo moderno. Así, alejado de cualquier sectarismo, que no de una identidad que le es propia como franciscano, se declara liberado de la esclavitud a las Escuelas, sean estas franciscanas o no $\mathrm{y}$ es consciente de que su reflexión sobre los asuntos (jurisconsultos, de iure, herejías...) han de tener en cuenta el contexto de la expresión teológico-pastoral.

En Adversus omnes haereses reafirma su posición no apegado a la Escuela de Salamanca, sino nacida del espíritu de la Universidad Complutense y la adopción de las tres vías y de la importancia de la libertad del humanismo y de la Sagrada Escritura en la teología cuando afirma que, admirando la sabiduría de Tomás de Aquino, Escoto u Ockham, difícilmente podrán decir de él que es tomista, escotista u ockhamista ${ }^{43}$, y es que aunque venere la santidad de Tomás de Aquino, nos expresa que "no por eso pienso que se deba opinar como él absolutamente en todo" 44 . Todo ello provoca que utilice la doctrina del Doctor Angélico de forma continuada, primordialmente, en aquellos temas que éste tenía más desarrollados que otros autores, como el caso de Juan Duns Escoto. Ahora bien, franciscanismo obliga y, sobre todo, la profundidad del personaje y su pensamiento, no duda en citar Escoto, especialmente cuando juzga es mal interpretado.

Nos encontramos a un Alfonso de Castro, de espíritu franciscano, instruido en las fuentes de su Religión, pero gran conocedor del humanismo, muy presente en la Orden Franciscana (como se puede observar en las bibliotecas del Nuevo Mundo $^{45}$ ). Y, especialmente sensible a las fuentes doctrinales de su época y a los nuevos retos intelectuales, dogmáticos y teológicos, tanto en lo referente a lo que se avecina, como a la doctrina elaborada en Salamanca, lugar donde desarrolla su docencia. Este espíritu profundo choca muchas veces con el enfoque nominalista y analítico de la reflexión filosófico-jurídica actual o con la autoreferencialidad de las posiciones nacidas de una Teoría [metalingüística] del

43 "Ego enim miserrimam hanc dicerem servitutem, sic esse humanæ sententiæ addictum, ut non liceat ullo modo illi repugnare: qualem patiuntur hi qui se tantum beati Thomae, aut Scoti, aut Ochan dictis subjiciunt, ut ab eorum placitis, in quos jurasse videntur, nomina fortiantur, quidam Thomistæ, alii Scotistae, alii Ochanistae, appellati". Alphonsus a Castro, Adversus omnes haereses, lib 1, cap. 7, I, 19 B.

44 "Ego quidem beati Thomæ sanctitatem veneror, ejus doctrinae multum tribuo, quod multum Ecclesiam illustraverit: non tamen puto adeo esse illi savendum, ut per omnia oporteat cum illo sentire". Alphonsus a Castro, Adversus omnes haereses, lib 1, cap. 7, I, 19b D-E.

45 En sus bibliotecas encontramos la presencia de un buen número de obras "humanísticas" y de autores clásicos como Platón, Plinio, Cicerón, Virgilio, Terencio, Aristóteles, Valerio Máximo, Quintiliano, Cicerón, Nebrija, Vives... También se dejan ver muchas obras de los Santos Padres, de Derecho, de comentarios a la Sagrada Escritura y de manuales de moral, historia, apologética y mística, así como otras obras de filosofía, teología y gramáticas de la lengua griega y hebrea. Cf. Lino Gómez, Evangelización, cultura y promoción social. Ensayos y estudios críticos sobre la contribución franciscana a los orígenes cristianos de México (siglos XVI-XVIII), selección y presentación por José Luis Soto Pérez (México: Editorial Porrúa, 1993), 409-415. 
Derecho, pero implican la longitud (profundidad natural y sobrenatural, teológico-filosófica, antropológica) y la extensión (sus relaciones interdisciplinares) semántica, referencial y ontológica de los conceptos jurídicos.

Dos obras pueden ser mencionadas en la faceta jurídica, el De iusta haereticorum punitione, libri tres y el De potestate legis poenalis libri duo. Esta segunda ha sido la más estudiada, señalaremos algunas breves líneas de la primera que es menos conocida.

\section{DE JUSTA HAERETICORUM PUNITIONE, LIBRI TRES}

Esta es la segunda obra publicada por Alfonso de Castro en la que profundiza el tema del libro anterior sobre las herejías, pero realizando un giro en el tratamiento. Si en el Adversus omnes haereses, Alfonso de Castro se ha fijado en las diferentes herejías, estableciendo el catálogo temático, en esta obro pone en evidencia el problema que la herejía supone en relación con la mediación eclesial en toda su extensión. Los herejes niegan la jerarquía eclesiástica, tanto la primacía de Pedro, como el grado de sacerdocio de los obispos y los sacerdotes. Esta mediación afecta tanto al culto y el aspecto litúrgico-ceremonial, como especialmente a los sacramentos, instituidos, señala el fraile zamorano, por tradición apostólica, y continuada por la tradición eclesial. Esto supone introducir novedades que disminuyen la eficacia de la gracia sacramental, dejando al pueblo, más vulnerable ante el pecado (haciendo referencia al sacramento de la penitencia). Esta ruptura de la mediación eclesial implica la banalización de las promesas sacerdotales, toda vez que niegan el celibato de todo el clero, al tiempo que socaban la posibilidad de realizar en vida las virtudes escatológicas (castidad, pobreza y obediencia), que suponen la vida religiosa ${ }^{46}$.

En esta obra aparece el teólogo en su versión más jurista, donde la teología se pone al servicio del derecho, y especialmente del derecho positivo penal, tanto al derecho civil como al canónico ${ }^{47}$. Esta obra podría bien encuadrarse en la faceta de la que hablamos a continuación: la del teólogo-jurista. El problema que la obra pretende responder es el de la situación ante la negación de los

46 "Primatum Petri negant, omnibus Christianis sacerdotia sine discrimine tribuunt. Sacerdotes omnes pares Episcopis faciunt, antiquas omnes Eclesiæ cæremonias ab ipsis Apostolis traditas, et ad hoc usque sæculum servatas, tollunt: et novas quasdam ab illis excogitatas, invehunt. Sacramenta Ecclesiæ minuunt, quo pauciora peccatorum antidota illa retineat. Ut autem nihil utile se Ecclesiæ detraxisse persuaderent, sacramentorum virtutem, atque potentiam negantes venenum veneno addiderunt. Toties cleri coelibatum tollunt. Vota omnia Deo facta violare docent. Omnem monachatus Religionem ab Ecclesia rejiciunt". Alphonsus a Castro, De justa haereticorum punitione, libri tres, "Epistola a Carlos V”, II, 1a C.

47 Antonio, "F. Alphonsus de Castro", 17a. 
interlocutores herejes frente al razonamiento y el relapso, o la reincidencia voluntaria.

Es decir, ¿qué hacer frente a los herejes que no hacen caso a las sugerencias de la razón teológica? Y, en segundo lugar, siendo así que es necesario aplicar el derecho y ello lleva implícito una pena y una medida correctiva, ¿cómo debe aplicarse el castigo de una forma teológicamente justificada, digamos con empeño pastoral, y no menos con una intención justificadora de la acción del emperador?

Para ello Alfonso de Castro estudiará en el Libro Primero, el objeto de aquello que debe ser juzgado. Se pregunta qué es la herejía, cuál es el mal que inflige, cuáles son las diferentes tipificaciones, a quién llamamos hereje, cómo solucionar la duda sobre si alguien es o no hereje, qué supone una actitud pertinaz, qué tipología de herejías existe, no en tanto a la materia cuanto al modo: magia, maledicencia, apostasía.

En el Libro Segundo investiga sobre el carácter judicial de la herejía. En qué sentido entendemos una actitud incorregible en el hereje (el relapso), qué sea entendido como justo y necesario a la hora de castigar a los herejes, argumentaciones frente a ciertas objeciones que ponen reparos en castigar a los herejes, el tipo de castigo infringido sea corporal o espiritual y las confiscaciones de los bienes temporales, la pena a los heréticos relacionada con la privación del dominio sobre los súbditos y razones para sostener esto, la reflexión sobre las penas morales como la infamia, la cuestión de si es lícito la respuesta bélica frente a los herejes, la excomunión postmortem, la respuesta sobre la potestad (potestad de orden) que se tiene cuando los herejes son obispos o sacerdotes, o incluso si fuera el Papa, si la pena de un hereje debe afectar a los hijos cuando estos acusan a sus padres de herejía... Todos estos razonamientos se van exponiendo, solventando en diferentes capítulos algunas objeciones. La secuencia de las cuestiones, nos hacen ver el entorno sociopolítico en el que las nuevas herejías se están dando, como se ve en el caso de los bienes temporales o la privación del dominio sobre los súbditos.

Por último, el Libro Tercero, más breve, se trata de un tratado filosófico y pedagógico sobre la naturaleza de las herejías. Alfonso de Castro intenta determinar sus causas con el fin de poder evitar nuevas herejías: la causa extrínseca del defecto en la predicación de la Palabra de Dios, la predicación que causa indiferencia y no afecta el espíritu de los fieles, la negligencia de los obispos y otros pastores de la Iglesia, la indignidad de muchos obispos y sacerdotes, los defectos de las traducciones de la Sagrada Escritura a lengua vulgar, la lectura asidua e incauta de no pocos tratados realizados por hombres gentiles, es decir 
la falta de formación a la hora de entender la filosofía clásica, especialmente la filosofía práctica como el hedonismo de Epicuro, o algunos errores de los filósofos, que caen en la felicidad natural olvidando la fuente sobrenatural, y que, por lo tanto, precisan de buen juicio ${ }^{48}$.

Termina el libro, recurriendo a la ya citada labor pedagógica, con la proposición del remedio contra la causa de la herejía que recae en la buena formación humanística del Pueblo de Dios que le preparare para poder interpretar los libros que en su tiempo están circulando ${ }^{49}$. Esto, dice, es algo que pueden hacer los príncipes fácilmente, incrementando preceptores. También la Iglesia debe preparar mejor a los sacerdotes, de modo que se estudie los principios de la filosofía en sus universidades, recordando explícitamente lo señalado en el Concilio V de Letrán (1513-1521), en su sesión $8^{\mathrm{a}}$ (1513), en la que se afrontaba el error de la inmortalidad del alma humana defendida por Pietro Pomponazzi (1462-1525) en el tratado De immortalitate animae, representado la renovación del averroísmo $^{50}$. Se trata, pues -y a eso llama y convoca esta obra- de nutrir de herramientas al Pueblo de Dios para que aprenda a discernir, siendo la pedagogía la mejor forma de luchar contra la herejía, de modo que se pueda bien iluminado el espíritu saber realizar la elección correcta, y esa es una obligación tanto del poder religioso como del poder temporal: nutrir espiritualmente al pueblo ${ }^{51}$.

48 "Nam hi omnes ignorantes Dei potentiam, ex cujus arbitrio omnia pendent, \& solum ordinem causarum naturalium considerantes, nihil voluntati divinæ, sed omnia necessitati tribuerunt. Qui autem apertius ostendit á philosophorum doctrina se suisse deceptum, fuit Petrus Abailardus, qui dixit nihil esse credendum, quod ratione naturali probari non possit. Et unde hoc nisi a philosophis oritur? Nam hi omnem doctrinam ex sola fui intelletus capacitate metiri volunt; \& quae suo judicio non conveniunt, statim rejiciunt; nihil denique recipere volunt, quod intellectus ratione natural comprehendere non possint". Alphonsus a Castro, De justa haereticorum punitione, libri tres, lib. 3, cap. 8, II, 231a A

49 "Primi qui savere debent, \& possuat, sunt præceptores, \& magistri, qui Gentilium libros aliis interpretantur". Alphonsus a Castro, De justa haereticorum punitione, libri tres, lib. 3, cap. 9, II, 234b C.

50 "absque divinae sapientis condimento, \& quae fine revelatae veritatis lumine in errorem quandoque magis inducunt, quam in veritatis elucidationem: ad tollendam omnem im praemissis errandi ocasionem, hac salutari constitutiones ordinamus \& statuimus, ne quisdam de cetero in sacris ordinibus constitutus, saecularia vel regularía, aut alias ad illos a jure arctatus, in studiis generalibus, vel alibi publicae audiendo, pulosophiae aut poesis studiis ultra quinquennium post grammaticam ae dialecticam, isno aliquo studio thologiae aut juris pontificii, incumbat... unde infestas philosohia \& poesis radice purgare \& sanare valeant. Et hos canones per ordinários locorum, ubi generalia studia vigente, de rectores universtitatis eorundem studiorum singulis annis in principio studii, in virtute santae obedentiae publicari mandamus". Leonis X. Concilio Lateranense V, 843a.

51 "Fateor quidem Episcoporum \& aliorum Ecclesiasticorum Rectorum proprium munus esse, ut tamquam communes populi Christiani nutrices illum lacte verbi Dei nutriant, \& fortiori, quum opus fuerit, cibo alant. Imperatoribus autem, \& Regibus, aliisque omnibus saeculi Principibus incumbit: ut populum sibi commissum a publicis fidei hostibus pro viribus defendere, $\&$ ipsos hostes, qui populo nocere tentant, punire conentur: ut poenarum me tu illi coerciti, sibi \& aliis sapere discant... Aliud praeterea vos o Reges \& Principes agere oportet , ut vos veros Ecclesiae nutritios juxta Dei praeceptum exhibeatis.”. Alphonsus a Castro, De justa haereticorum punitione, libri tres, lib. 3, "Adhortatio Auctoris ad Principes Christianos de justa hareticorum punitione", II, 236b D. 
Siendo una obra más teórica que el Adversus omnes haereses, que era mucho más positiva, el autor no vio la necesidad de revisarla. De esta forma, desde que salió de la imprenta, por primera vez, en 1547 en Salamanca y en sus ocho ediciones (otra más de Salamanca, dos en Venecia, tres de Lyon y una de Amberes) no sufrió modificaciones en el contenido. Tenemos ejemplares en diversas bibliotecas españolas y, también, en Francia, Italia y Colombia. La obra aparece, a su vez, en diversas Opera omnia y en dos ediciones parciales francesas del siglo XVII.

La obra De justa haereticarum punitione resume el pensamiento de Alfonso de Castro y la nueva forma de pensar del teólogo. Su renovada función orientadora de la sociedad, a partir de la lectura de la tradición ${ }^{52}$, constituyó el último bastión ante el nominalismo jurídico y el camino hacia la nihilidad.

\section{REFERENCIAS BIBLIOGRÁFICAS}

Alberigo, Giuseppe. Chiesa conciliare: Identità e significato del conciliarismo. Brescia: Paideia Ed. Istituto per le Scienze Religiose, 1981.

Amor y Neveiro. Constante. Examen crítico de las nuevas escuelas de derecho Penal. Madrid: Imprenta del Asilo de huérfanos del Sagrado Corazón de Jesús, 1899.

Andrés, Melquiades. "La Teología en el siglo XVI (1470-1580)". En Historia de la Teología Española. I. Desde sus orígenes hasta finales del siglo XVI, dirigido por Melquiades Andrés, 579-735. Madrid: Fundación Universitaria Española, 1983.

—. La teología española en el siglo XVI, Vol. 2. Madrid: BAC, 1977.

Arias, Saturnino. "Herejía y hereje en Alfonso de Castro". Liceo Franciscano 12 (1958): 109-130.

Belda, Juan. La Escuela de Salamanca y la renovación de la teología en el siglo XVI. Madrid: BAC, 2000.

Bullón, Eloy. Alfonso de Castro, fundador del Derecho Penal. Madrid: Imp. Hijos de M. G. Hernández, 1900.

Castro, Alphonsus a. Opera Omnia, 2 vols. Madrid: Ex Typpographia Blassi Roman, 1773.

- Antología, selección y prólogo de Juan del Rosal. Madrid: Ediciones Fe, 1942.

- De potestate legis poenalis, Vol. 1 [edición facsímil Ed. Príncipe, Salamanca, Andreas de Portonariis, 1550] Madrid: Analecta Editorial, 1961.

52 Manuel Lázaro, "Una reflexión sobre la tradición y modernidad en Alfonso de Castro", Cauriensia 13 (2018): 459-478. 
De Dios, Salustiano. "Corrientes jurisprudenciales siglos XVI-XVII". En Historia de la Universidad de Salamanca, Vol. 3/1, editado por Luis E. Rodríguez-San Pedro y Juan Luis Polo, 75-102. Salamanca: Publicaciones universidad de Salamanca, 2006.

De Vooght, Paul. L'hérésie de Jean Huss. Louvain: Publications Universitaires de Louvain, 1960.

Gancho, Claudio. "La Biblia en Alfonso de Castro". Salmanticensis, 6 (1958): 323-349.

García, Antonio. "Juristas salmantinos, siglos XIV-XV: manuscritos e impresos". En Historia de la Universidad de Salamanca, Vol. 3/1, editado por Luis E. Rodríguez-San Pedro y Juan Luis Polo, 103-119. Salamanca: Publicaciones universidad de Salamanca, 2006.

García, José. "Conventualismo y Observancia". En Historia de la Iglesia en España. III/1. La Iglesia en la España de los siglos XV y XVI, editado por Ricardo García-Villoslada, 211-345. Madrid: BAC, 1980.

-. Los Franciscanos en España. Historia de un Itinerario Religioso. Santiago de Compostela: El Eco Franciscano, 2006.

García, José y Segundo L. Pérez, "La reforma religiosa durante la gobernación del Cardenal Cisneros (1516-1518): hacia la consolidación de un largo proceso". Annuarium Sancti Iacobi 1 (2012): 47-174.

García-Villoslada, Ricardo. "Fray Francisco de Vitoria, reformador de los métodos de la teología católica". En Fray Francisco de Vitoria, fundador del derecho internacional moderno, 65-66. Madrid: Cultura Hispánica, 1946.

Gómez, Lino. Evangelización, cultura y promoción social. Ensayos y estudios críticos sobre la contribución franciscana a los orígenes cristianos de México (siglos XVI-XVIII), selección y presentación por José Luis Soto Pérez. México: Editorial Porrúa, 1993.

González, Amado. "Vida y Bibliografía de Fray Alfonso de Castro". Liceo Franciscano 12 (1958): 1-106.

Gutiérrez, Luis Miguel. "Aproximación a la historia de la Universidad de Alcalá (siglos XVI-XIX)". Indagación. Revista de historia y arte 0 (1994): 15-37.

Lázaro, Manuel. "Posiciones antropológico-jurídicas en el Tratado La fuerza de la ley penal de Alfonso de Castro". En Razón práctica y derecho. Cuestiones filosófico-jurídicas en el Siglo de Oro español, editado por Juan Cruz, 138-143. Pamplona: Eunsa, 2011.

- "La naturaleza de la natura: un apunte sobre mística y ciencia en el franciscanismo medieval de la Península Ibérica". Scientia et fides 6/2 (2018): 129-146.

—. "Una reflexión sobre la tradición y modernidad en Alfonso de Castro", Cauriensia 13 (2018): 459-478. 
Le Bras, Gabriel. "La formation du droit romano-canonique". En Actes du congrès de droit canonique, Cinquantenaire de la Faculté de droit canonique de l'Institut catholique de Paris (1947), dirigido por Pierrre Andrieu-Guitrancourt, 335-338. Paris: Letouzey et Ané, 1950.

Leff, Gordon. Heresy in the Later Middle Ages, vol. 2. Manchester: Manchester University Press, 1967.

Maihold, Harald. "Systematiker der Häresien - Erinnerung an Alphonso de Castro (1492-1558)". Zeitschrift der Savigny-Stiftung für Rechtsgeschichte, Kanonistische Abteilung 118 (2001): 523-530.

Maseveu, Jaime. Contribución al estudio de la Escuela penal española. Madrid: Gráfica Ambos Mundos, 1922.

Martínez, Francisco. "Textos y contextos de la teología franciscana". En Manual de Teología franciscana, editado por José Antonio Merino y Francisco Martínez, 3-56. Madrid: B.A.C., 2003.

Montes, Jerónimo. Precursores de la Ciencia Penal en España y las causas y remedios del delito. Madrid: Lib. General V. Suárez, 1911.

Müller, Daniela. "Ketzerei und Ketzerbestrafung im Werk des Alfonso de Castro". En Die Ordnung der Praxis. Neue Studien zur Spanischen Spät-scholastik, editado por Frank Grunert y Kurt Seelmann, 333-348. Tübingen: Max Niemeyer Verlag, 2001.

Merryman, John Henry y Rogelio Pérez-Perdomo. La tradición jurídica romano-canónica, $3^{\mathrm{a}}$ ed. México: Fondo de cultura Económica, 2014.

Pazos, Manuel R. Los estudios en la provincia franciscana de Santiago (Tratado histórico). Madrid: Escuelas profesionales Sagrado Corazón de Jesús, 1967.

Pena, Miguel Anxo. La Escuela de Salamanca. De la Monarquía hispánica al Orbe católico. Madrid: BAC, 2009.

Pérez-Llantada, Jaime. "Derecho civil (ius civile)". En Diccionario de Derecho canónico, dirigido por Carlos Corral, $2^{\mathrm{a}}$ ed., 221-223. Madrid: Tecnos, 2000.

Rodríguez, Marcelino. Origen español de la ciencia del derecho penal. Alfonso de Castro y su sistema de derecho penal. Madrid: Ed. Cisneros, 1959.

-. Alfonso de Castro y su doctrina penal. El origen de la ciencia del derecho penal. Pamplona: Eunsa, 2013.

Rouco, Antonio María. Teología y Derecho: escritos sobre aspectos fundamentales de Derecho Canónico y de las relaciones Iglesia-Estado, editado por Roberto Serres. Madrid: Cristiandad, 2003.

Santaella, Manuel. Montesquieu. El legislador y el arte de legislar. Madrid: UPCO, 1995.

Savall, Domingo. "Fr. Alfonso de Castro (1495-1558). La orientación voluntarista de su derecho penal". Revista de Archivo Ibero-Americano 38 (1935): 240-255. 
Tomás y Valiente, Francisco. El Derecho penal de la Monarquía absoluta (siglos XVI- XVII-XVIII). Madrid: Tecnos, 1969.

Urriza, Juan. La preclara Facultad de Arte y Filosofia de la Universidad de Alcalá 1509-1621. Madrid: CSIC, 1941.

Manuel Lázaro Pulido

Departamento de Filosofía Facultad de Filosofía

UNED

Calle Paseo Senda del Rey, 7

(Edificio de Humanidades) 28040 Madrid (Espana) https://orcid.org/0000-0002-0064-5293
Departamento de Ciencias del Derecho

Escuela de Derecho Universidad Bernardo O'Higgins

Cl. General Gana 1702 Metro Rondizzoni Santiago (Chile). 